the questions here discussed will be treated in greater detail. In this letter it is my intention only to direct attention to the possibilities which the elaboration of the principles underlying the spectral applications of the quantum theory seems to open for the interpretation of other properties of the elements. In this connection I should also like to mention that it seems possible, from the examination of the change of the spectra of the elements in the presence of magnetic fields, to develop an argument which promises to throw light on the difficulties which have hitherto been involved in the explanation of the characteristic magnetic properties of the elements, and have been discussed in various recent letters in NATURE.

N. BOHR.

Copenhagen, February I4.

\section{The Dimensions of Atoms and Molecules.}

Certain relations which are to be traced between the distances separating atoms in a crystal make it possible to estimate the distance between their centres when linked together in chemical combination. On the Lewis-Langmuir theory of atomic constitution, two electro-negative elements when combined hold one or more pairs of electrons in common, so that the outer electron shell of one atom may be regarded as coincident with that of the other at the point where the atoms are linked together. From this point of view, estimates may be made (W. L. Bragg, Phil. Mag., vol. xi., August, 1920) from crystal data of the diameters of these outer shells. The outer shell of neon, for example, was estimated from the apparent diameters of the carbon, nitrogen, oxygen, and fluorine atoms, which show a gradual approximation to a minimum value of $1 \cdot 30 \times 10^{-8} \mathrm{~cm}$. The diameters of the inert gases as found in this way are given in the second column of the following table :

\begin{tabular}{|c|c|c|c|}
\hline Gas & $\begin{array}{c}\text { Diameter } 2 \sigma \\
\text { (Crystals) }\end{array}$ & $\begin{array}{l}\text { Diameter 2 } \sigma^{\prime} \\
\text { (Viscosity) }\end{array}$ & $\begin{array}{l}\text { Difference } \\
2 \sigma^{\prime}-2 \sigma\end{array}$ \\
\hline Helium & $\ldots \quad-$ & $\mathrm{I} \cdot 89$ & - \\
\hline Neon $\ldots$ & $I \cdot 30$ & $2 \cdot 35$ & $\mathrm{I} \cdot 05$ \\
\hline Argon & 2.05 & 2.87 & 0.82 \\
\hline Krypton & $2 \cdot 35$ & 3.19 & 0.84 \\
\hline Xenon & 2.50 & 3.51 & $0.8 \mathrm{r}$ \\
\hline
\end{tabular}

In the third column are given Rankine's values (A. O. Rankine, Proc. Roy. Soc., A, vol. xcviii., 693, pp. $360-74$, February, I92 I) for the diameters of the inert gases calculated from their viscosities by Chapman's formula (S. Chapman, Phil. Trans. Roy. Soc., A, vol. ccxvi., pp. 279-348, December, I9I5). These are considerably greater than the diameters calculated from crystals, but this is not surprising in view of our ignorance both of the field of force surrounding the outer electron shells and of the nature of the electron-sharing which links the atoms together, for it is quite possible that their structures might coalesce to a considerable extent. The constancy of the differences between the two estimates given in the fourth column shows that the increase in the size of the atom as each successive electron shell is added is nearly the same (except in the case of neon), whether measured by viscosity or by the crystal data. Further, Rankine has shown that the molecule $\mathrm{Cl}_{2}$ behaves as regards its viscosity like two argon atoms with a distance between their centres very closely equal to that calculated from crystals, and that the same is true for the pairs $\mathrm{Br}_{2}$ and krypton, $\mathrm{I}_{2}$ and xenon.

We see, therefore, that the evidence both of crystals and viscosity measurements indicates that $(a)$ the elements at the end of any one period in the periodic table are very nearly identical as regards the diameters NO. 2682 , VOL. IO7] of their outer electron shells, and $(b)$ in passing from one period to the next there is a definite increase in the dimensions of the outer electron shell, the absolute amount of this increase estimated by viscosity agreeing closely with that determined from crystal measurements.

A further check on these measurements is afforded by the infra-red absorption spectra of $\mathrm{HF}, \mathrm{HCl}$, and $\mathrm{HBr}$. The wave-number difference $\delta v$ between suc. cessive absorption lines determines the moment of inertia I of the molecule in each case, the formula being

$$
\delta \nu=\frac{h}{4 \pi^{2} c \mathrm{I}},
$$

where $h$ is Planck's constant and $c$ the velocity of light.

It is therefore possible to calculate the distances between the centres of the nuclei in each molecule, for

$$
s^{2}=\frac{m+m^{\prime}}{m m^{\prime}} \cdot \frac{h}{4 \pi^{2} c m_{\mathrm{r}} \delta \nu}
$$

where $m$ and $m^{\prime}$ are the atomic weights relative to hydrogen and $m_{\mathrm{r}}$ the mass of the hydrogen atom. The following table gives these distances (E. S. Imes, Astroph. Journal, vol. 1., p. 25I, I9r9). It will be seen that there are again increases in passing from $\mathrm{F}$ to $\mathrm{Cl}$ and $\mathrm{Cl}$ to $\mathrm{Br}$, which agree closely with the increases in the radii $\sigma$ of the electron shells given by the crystal and viscosity data.

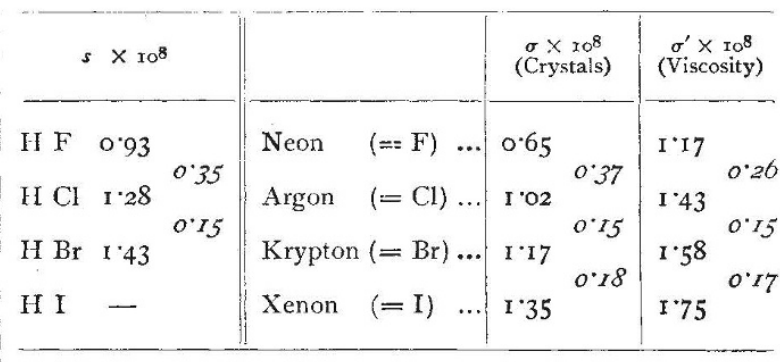

The increase from fluorine to chlorine of $0.35 \times \mathrm{ro}^{-8} \mathrm{~cm}$. confirms the estimate given by crystals of $0.37 \times 10^{-8} \mathrm{~cm}$. , as against the estimate $0.26 \times$ Io $^{-8} \mathrm{~cm}$. given by viscosity data. It follows from the above that the distance between the hydrogen nucleus and the centre of an electro-negative atom to which it is attached is obtained by adding $0.26 \times 10^{-2} \mathrm{~cm}$. to the radius of the electro-negative atom as given by crystal structures. The radius of the inner electron orbit, according to Bohr's theory, is $0.53 \times 10^{-1} \mathrm{~cm}$. , double this value. The crystal data, therefore, predict the value $\delta v=13.0 \mathrm{~cm} \cdot{ }^{-i}$ for the HI molecule, corresponding to a distance $\mathrm{r} \cdot 6 \mathrm{I} \times \mathrm{IO}^{-1} \mathrm{~cm}$. between their atomic centres.

This evidence is interesting as indicating that the forces binding the atoms together are localised at that part of the electron shell where linking takes place.

Manchester University, March 16.

\section{W. L. BRAGG.}

H. BeLl.

\section{The International Research Council.}

THE object of this council, says Sir Arthur Schuster in NATURE of March 17 , is "to reorganise international work which had come to a standstill through the war, and to extend it where found desirable." It may be worth while to consider for a moment how the council has set to work to promote these innocent and laudable ends. 